\title{
CAST IN-SITU TIAI-BASED MATRIX COMPOSITES REINFORCED WITH CARBIDE PARTICLES
}

\author{
Juraj LAPIN \\ Institute of Materials and Machine Mechanics, Slovak Academy of Sciences, Bratislava, \\ Slovak Republic, EU, juraj.lapin@savba.sk
}

https://doi.org/10.37904/metal.2019.747

\begin{abstract}
In-situ TiAl-based matrix composites reinforced with ceramic particles can improve the deficiency of lightweight TiAl-based alloys at high temperatures and facilitate their industrial applications using well-known and widely applied processing technologies. Carbide particles show a significant role in toughening and reinforcing of TiAl-based matrix composites. Among various techniques applied for processing of in-situ composites, precise casting is of large industrial interest for the production of complex shaped components such as turbocharger wheels or turbine blades. This paper reviews developments in cast in-situ TiAl-based matrix composites reinforced with carbide particles concentrating on the last four years and drawing examples from the three most widely researched systems with near $\gamma(\mathrm{TiAl})$, duplex and fully lamellar $\alpha_{2}\left(\mathrm{Ti}{ }_{3} \mathrm{Al}\right)+\gamma(\mathrm{TiAl})$ matrices. The effect of processing techniques on microstructure and high temperature mechanical properties of designed composite systems is presented and discussed.
\end{abstract}

Keywords: TiAl, composites, casting; mechanical properties, microstructure

\section{INTRODUCTION}

In-situ intermetallic matrix composites, where a thermodynamically stable discontinuous reinforcing phases are formed during solidification and solid-state phase transformations, may improve low strength of lightweight TiAl-based alloys at high temperatures (above $800^{\circ} \mathrm{C}$ ) [1,2]. The advantages of in-situ composites as compared to ex-situ composites, where the reinforcing phase is synthesized separately and then inserted into the intermetallic matrix, include: (i) smaller reinforcement size, (ii) small single crystal reinforcement, (iii) clean particle-matrix interfaces with higher strength, (iv) thermodynamically stable particles, (v) better particle-size distribution and (vi) application of conventional processing techniques [3]. Several ceramics have been proposed as the reinforcement of the TiAl-based alloys [4-8]. Among these ceramics, the Ti2AIC phase possesses a unique combination of both metallic and ceramic properties such as high fracture resistance, excellent damage tolerance, good thermal and electrical conductivity, easy machinability, good thermal shock and oxidation resistance, high elastic modulus and thermomechanical stability [9-11]. Furthermore, the density and thermal expansion coefficient of the $\mathrm{Ti}_{2} \mathrm{AlC}$ are close to those of the TiAl-based alloys, which would largely avoid the phenomena of segregation of the carbide particles and reduce inner stresses between the reinforcement and the matrix during fabrication. Besides the coarse primary $\mathrm{Ti}_{2} \mathrm{AIC}$ particles $[1,12]$, additional strengthening can be achieved by fine secondary $\mathrm{P}-\mathrm{Ti} 3 \mathrm{AIC}_{3}$ and $\mathrm{H}-\mathrm{Ti}_{2} \mathrm{AIC}$ precipitates similarly to that reported for several low carbon-containing TiAl-based alloys [13-16].

Various techniques including powder metallurgy, mechanical alloying, reactive hot pressing, plasma spark sintering, vacuum arc melting and combustion synthesis have been applied for processing of in-situ TiAl matrix composites [17-21]. Among these techniques, melting and casting are of large interest for the production of complex-shaped components in a cost-effective way. Several crucible and mould materials have been evaluated for melting and casting of TiAl-based alloys. The ceramic showing the highest thermochemical stability such as $\mathrm{Y}_{2} \mathrm{O}_{3}$ is expensive and $\mathrm{CaO}$ is sensitive to the humidity. On the other hand, the graphite is a cheap material with a good formability. Hence, it is of large interest to evaluate the potential of the graphite crucibles and moulds for processing of in-situ TiAl-based matrix composites reinforced with carbide particles. 
There is lack of information about specific features of carbide reinforcement formed in microstructurally different types of matrices and high temperature deformation behaviour of such composites.

The aim of this paper is to review development in vacuum induction melted and cast in-situ TiAl-based matrix composites reinforced with carbide particles and drawing examples from the three most widely researched systems with near $\gamma(\mathrm{TiAl})$, duplex and fully lamellar $\alpha_{2}\left(\mathrm{Ti}_{3} \mathrm{Al}\right)+\gamma(\mathrm{TiAl})$ matrices. The effect of processing techniques on microstructure and high temperature mechanical properties is presented and discussed.

\section{EXPERIMENTAL PROCEDURES}

Three types of in-situ composites with the chemical composition Ti-44.5Al-8Nb-0.8Mo-3.6C-0.1B (G1-36), Ti37Al-7Nb-0.8Mo-5.9C-0.1B (G2-59) and Ti-46.4Al-5Nb-1C-0.2B (KK-10) (in at\%) were prepared by vacuum induction melting in the graphite crucibles which was followed by a centrifugal casting into cold graphite moulds with different inner cavity diameters ranging from 12 to $17 \mathrm{~mm}$ and length of $150 \mathrm{~mm}$. The as-cast samples were subjected to hot isostatic pressing (HIP) at $200 \mathrm{MPa}$ for $4 \mathrm{~h}$ to remove casting porosity. The in-situ composite G1-36 was HIP-ed at $1250{ }^{\circ} \mathrm{C}$ and stabilisation annealed at $900{ }^{\circ} \mathrm{C}$ for $20 \mathrm{~h}$ in air. The in-situ composite G2-59 was HIP-ed at $1250{ }^{\circ} \mathrm{C}$, solution annealed at $1380^{\circ} \mathrm{C}$ for $1 \mathrm{~h}$ and stabilisation annealed at $950^{\circ} \mathrm{C}$ for $50 \mathrm{~h}$ in air. The in-situ composite KK-10 was HIP-ed at $1360^{\circ} \mathrm{C}$, which led to significant grain growth. In order to refine the coarse-grained microstructure, the KK-10 was subjected to additional heat treatments described in detail elsewhere [14].

Compression tests were carried out on cylindrical specimens with a diameter of $10 \mathrm{~mm}$ and length of $15 \mathrm{~mm}$ at a temperature of $1000{ }^{\circ} \mathrm{C}$ and initial strain rate of $1 \times 10^{-4} \mathrm{~s}^{-1}$ using a thermo-mechanical tester Gleeble 3800. The compression true stress-true strain curves were calculated from the measured engineering compression stress-strain data using the procedure described elsewhere [22].

Cylindrical creep specimens with a gauge diameter of $6 \mathrm{~mm}$ and gauge length of $30 \mathrm{~mm}$ were lathe machined from the heat treated $(\mathrm{HT})$ in-situ composites. Constant load tensile creep tests were carried out at a temperature of $850{ }^{\circ} \mathrm{C}$ under initial stress of $200 \mathrm{MPa}$ in air. The treatment of creep data was carried out using the procedure described elsewhere [23].

Microstructure evaluation was performed by scanning electron microscopy (SEM), SEM in back-scattered electron (BSE) mode, transmission electron microscopy (TEM), X-ray diffraction (XRD) analysis and energydispersive X-ray spectroscopy (EDS). TEM samples were thinned mechanically and subsequently by ion milling to perforation. Volume fractions of coexisting phases were measured on digitalised SEM and BSE micrographs using a computerised image analyser.

\section{RESULTS AND DISCUSSION}

\subsection{Effect of processing techniques on microstructure}

Since TiAl-based alloys are known to have low castability and large solidification shrinkage rate which not only causes misrun defects on surface of components but also results frequently in shrinkage porosity and crack defects, extensive optimisation of processing parameters is required [24]. The optimised vacuum induction melting of the studied in-situ composites in the graphite crucibles followed by centrifugal casting into cold graphite moulds results in high surface quality, reduced shrinkage porosity, required chemical composition and microstructure reproducibility of the as-cast samples. I spite of optimisation of processing parameters, the castings still contain closed line porosity formed along their longitudinal axis and fine interdendritic porosity. Several authors have reported that the casting porosity in TiAl-based alloys and in-situ TiAl-based matrix composites can be removed by HIP $[1,25]$. Besides the closure of the porosity in the studied as-cast in-situ composites, the applied HIP at a temperature of $1360^{\circ} \mathrm{C}$, which corresponds to a phase field (Ti-based solid solution with hexagonal structure), leads also to grain growth in the KK-10 alloy. 

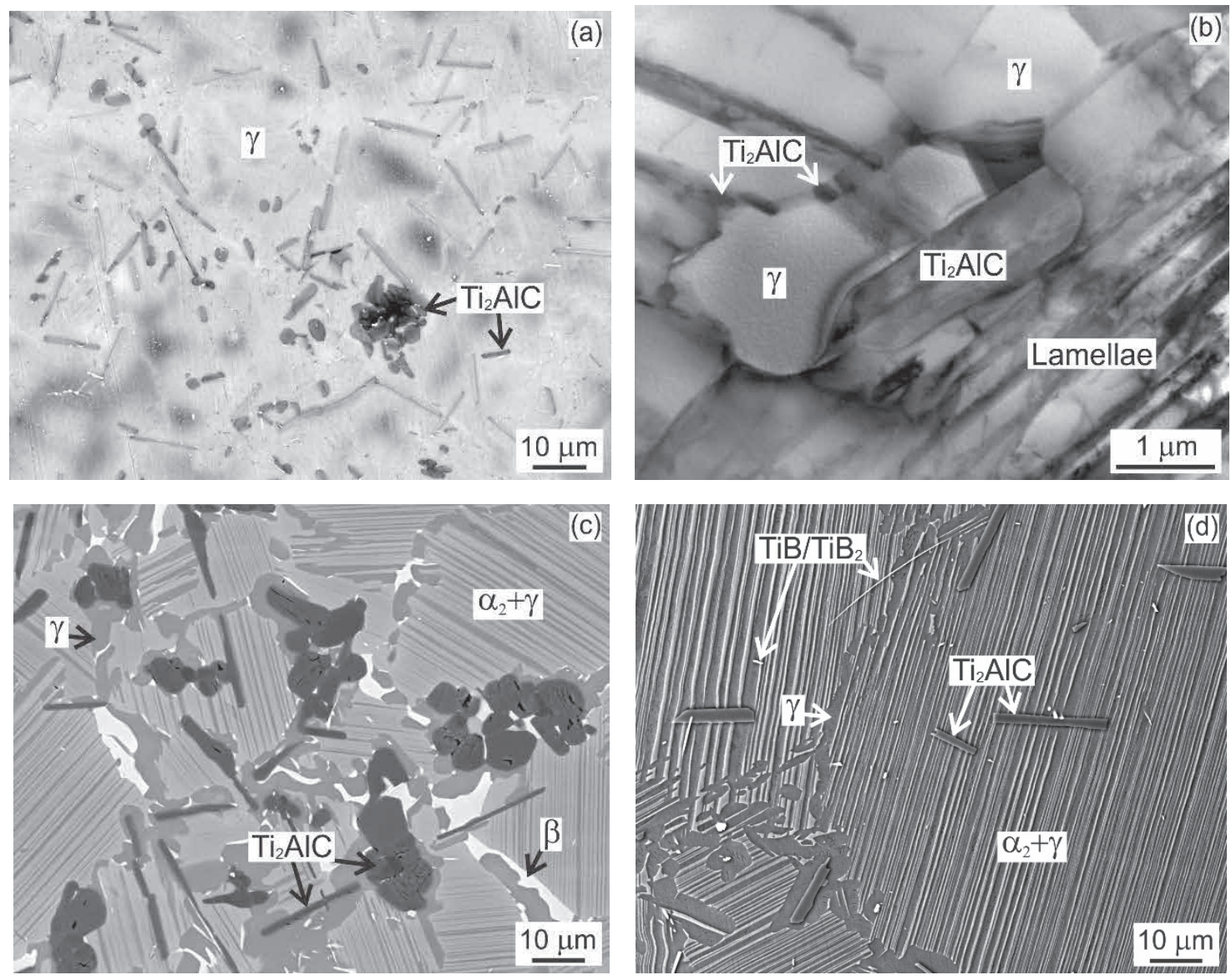

Figure 1 Microstructure of the studied in-situ composites after HIP and heat treatments: (a) G1-36, BSE; (b) G1-36, TEM; (c) G2-59, BSE; (d) KK-10, BSE

Figure 1 shows the typical microstructures of the studied in-situ composites designated as G1-36, G2-59 and KK-10 after the applied heat treatments. The microstructure of the in-situ composite G1-36 with the chemical composition Ti-44.5Al-8Nb-0.8Mo-3.6C-0.1B (at\%) consists of primary regular shaped, irregular shaped and plate-like carbide particles (14.6 vol.\%) uniformly distributed in the intermetallic matrix, as shown in Figure 1a. The EDS, XRD and TEM analysis showed that the carbide particles belong to $\mathrm{Ti}_{2} \mathrm{AIC}$ phase and the matrix is composed of $\gamma(\mathrm{TiAl})$ phase with fine secondary $\mathrm{H}-\mathrm{Ti}_{2} \mathrm{AIC}$ and $\mathrm{P}-\mathrm{Ti}_{3} \mathrm{AlC}$ precipitates, as seen in Figure 1b [1]. The microstructure of the heat treated in-situ composite G2-59 with the chemical composition Ti-37Al-7Nb0.8Mo-5.9C-0.1B (at\%) consists of regular shaped, irregular shaped and plate-like $\mathrm{Ti}_{2} \mathrm{AIC}$ particles (22.6 vol.\%) uniformly distributed in the duplex type of matrix composed lamellar $\alpha_{2}+\gamma$ grains surrounded by fine single phase $\gamma$ and $\beta$ (Ti-based solid solution with cubic crystal structure) grains, as shown in Figure 1c. The microstructure of the heat treated in-situ composite KK-10 with the chemical composition Ti-46.4Al-5Nb-1C$0.2 \mathrm{~B}($ at $\%)$ consists of plate-like $\mathrm{Ti}_{2} \mathrm{AlC}$ particles $(2.3 \mathrm{vol} . \%)$ and $\mathrm{TiB} / \mathrm{TiB}_{2}$ particles which are homogeneously distributed within the fully lamellar $\alpha_{2}+\gamma$ grains, as shown in Figure $1 \mathrm{~d}$.

\subsection{High-temperature mechanical properties}

The typical true stress-true strain compressive curves of the studied in-situ composites G1-36, G2-59 and KK10 tested at a temperature of $1000{ }^{\circ} \mathrm{C}$ under a strain rate of $1 \times 10^{-4}$ are presented in Figure 2. The true stress first increases sharply with increasing true strain. After reaching a peak flow stress value at a true strain of 2.2, 1.8 and $2.8 \%$ for the in-situ composite G1-36, G2-59 and KK-10, respectively, the true stress decreases with increasing true strain. 


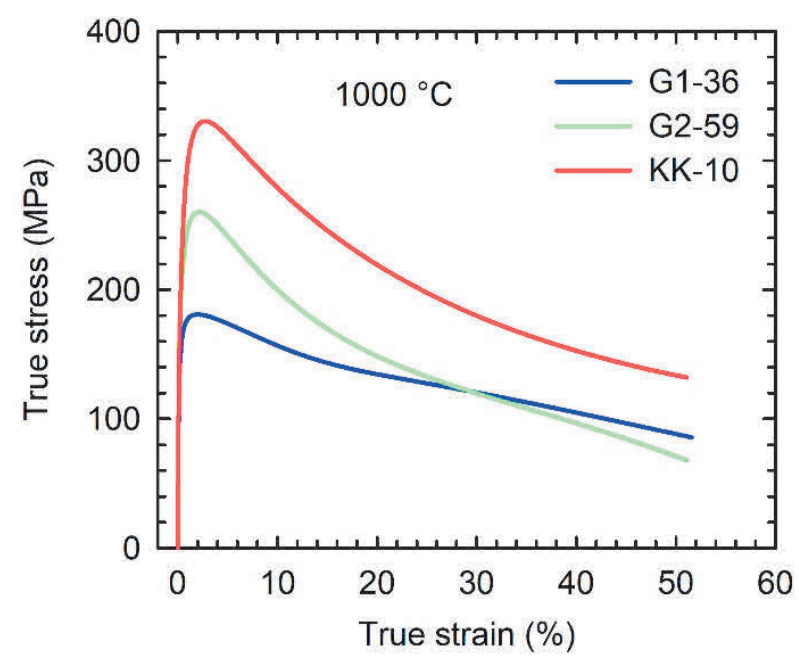

Figure 2 True stress-true strain compressive curves at $1000^{\circ} \mathrm{C}$

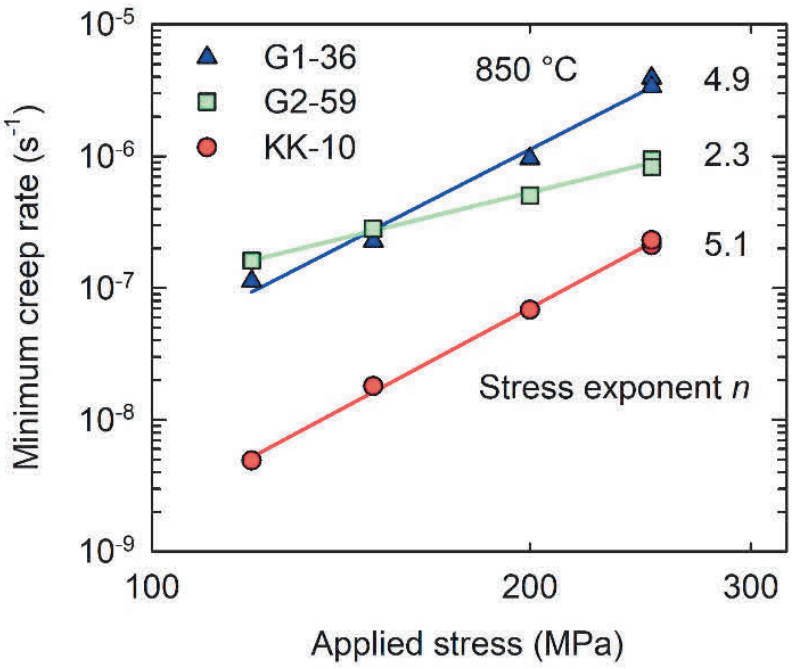

Figure 3 Dependence of minimum creep rate on the applied stress at $850^{\circ} \mathrm{C}$

For all studied in-situ composites, work hardening is the predominant mechanism at small strains due to an increment of dislocation density and deformation twins in the intermetallic matrix. The work softening of the insitu composites results from dynamic recovery, dynamic recrystallization and fragmentation of some coarse primary $\mathrm{Ti}_{2} \mathrm{AIC}$ particles. The high dislocation density at the matrix/particle interfaces provides the driving force for nucleation and growth of fine recrystallized $\gamma$ grains. The shape of the flow curves indicates a better balance between the work hardening and softening mechanisms operating in the coarse-grained fully lamellar in-situ composite KK-10 compared to that of the in-situ composites G1-36 and G2-59. The high peak flow stress of the KK-10 indicates an improvement in high-temperature strength, which is of large interest for applications demanding improved creep resistance.

The creep deformation curves of the studied in-situ composites exhibited short primary creep stage that is directly followed by the tertiary creep. During the primary creep stage, creep rate decreases with increasing strain. After reaching a minimum value, the creep rate increases with increasing strain. It is worth noting that no steady-state creep stage is observed at a temperature of $850^{\circ} \mathrm{C}$ and the applied stresses ranging from 150 to $250 \mathrm{MPa}$.

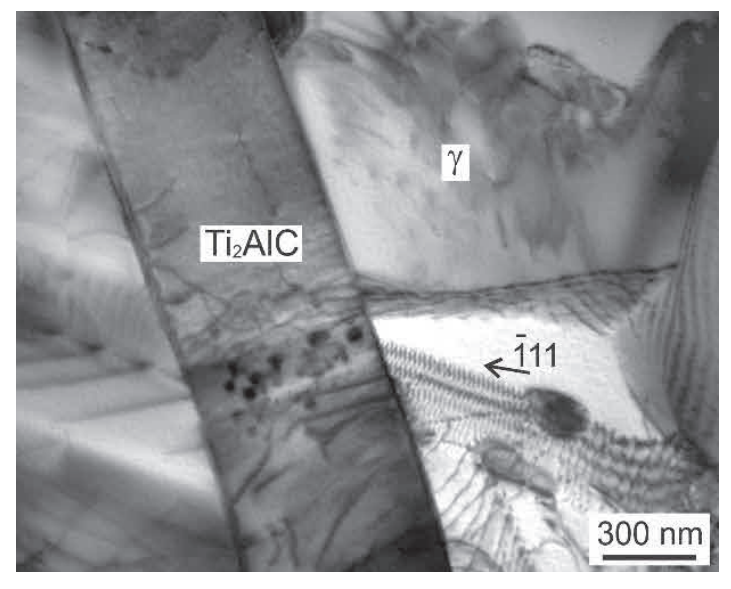

Figure 4 TEM micrograph showing deformation microstructure of in-situ composite G1-36

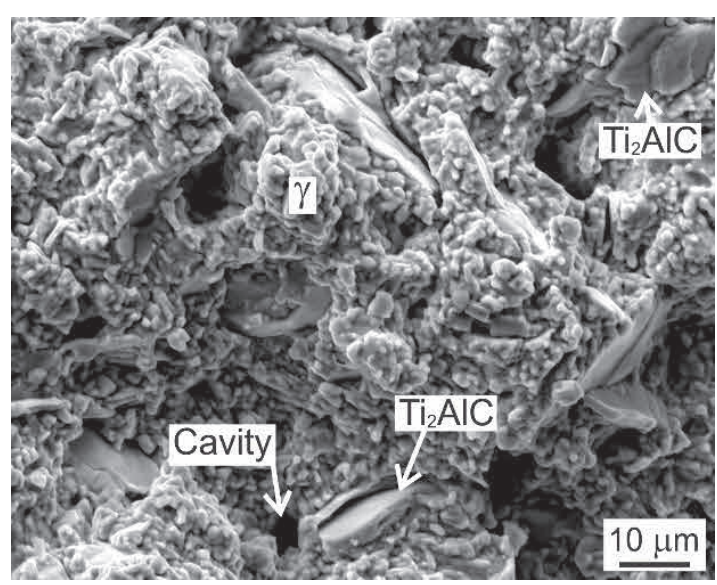

Figure 5 SEM micrograph showing fracture surface of creep specimen G1-36 
Figure 3 shows the dependence of the measured minimum creep rate on the applied stress. The measured minimum creep rates and applied stresses can be fitted to a power law equation described elsewhere [23]. Using linear regression analysis of the creep data, the stress exponent $n$ of the power law equation is determined to be 4.9, 2.3 and 5.1 for the in-situ composite G1-36, G2-59 and KK-10, respectively. The stress exponents of about 5 indicate that the kinetics of the creep deformation is controlled by diffusion assisted climb of dislocations in the in-situ composites G1-36 and KK-10. The measured stress exponent close to 2 indicates that the creep deformation of the in-situ composite G2-59 is controlled by grain boundary sliding. Figure 4 indicates that the favourably oriented primary $\mathrm{H}-\mathrm{Ti}_{2} \mathrm{AIC}$ particles deform plastically due to dislocation transfer from the matrix to the reinforcement. Figure 5 shows ductile fracture mode of the creep specimen G1-36. The cavities are formed at the matrix/particle interfaces and within the fractured coarse primary carbide particles. The cavity nucleation is controlled by diffusion and the number of cavities increases with increasing local strain within the gauge section of the creep specimens.

\section{CONCLUSION}

The recent developments in vacuum induction melted and centrifugally cast in-situ composites with fully lamellar, near $\gamma(\mathrm{TiAl})$ and duplex matrices reinforced with carbide particles are reviewed. The optimised melting and casting processes lead to high surface quality, required chemical composition, homogenous distribution of primary carbide particles and microstructure reproducibility of the in-situ composites. Besides the coarse primary $\mathrm{H}-\mathrm{Ti}_{2} \mathrm{AIC}$ particles, the additional strengthening of the TiAl-based matrices is achieved by fine secondary $\mathrm{P}-\mathrm{Ti}_{3} \mathrm{AIC}$ and $\mathrm{H}-\mathrm{Ti}_{2} \mathrm{AIC}$ particles. The porosity in the as-cast samples can be fully removed by HIP and the microstructure can be optimised by appropriate heat treatments. The in-situ composite with fully lamellar matrix reinforced with a low volume fraction of primary $\mathrm{Ti}_{2} \mathrm{AIC}$ particles and fine secondary precipitates show the highest improvement in high temperature strength and high potential for further development and optimisation.

\section{ACKNOWLEDGEMENTS}

\section{This work was financially supported by the Slovak Research and Development Agency under the contract APVV-15-0660.}

\section{REFERENCES}

[1] LAPIN, J., KLIMOVÁ, A., GABALCOVÁ, Z., PELACHOVÁ, T., BAJANA, O. and ŠTAMBORSKÁ, M. Microstructure and mechanical properties of cast in-situ TiAl matrix composites reinforced with (Ti,Nb) $)_{2} \mathrm{AIC}$ particles. Mater. Des. 2017. vol. 133, pp. 404-415. DOI: 10.1016/j.matdes.2017.08.012.

[2] ŠTAMBORSKÁ, M., LAPIN, J. and BAJANA, O. Effect of carbon on the room temperature compressive behaviour of Ti-44.5Al-8Nb-0.8Mo-x C alloys prepared by vacuum induction melting. Kovove Mater. 2018. vol. 56, pp. 349356. DOI: 10.4149/km_2018_6_349.

[3] AIKIN, R.M. The mechanical properties of in-situ composites. JOM. 1997. vol. 49, pp. 35-39. DOI: 10.1007/BF02914400.

[4] VOJTĚCH, D., LEJČEK, P., KOPEČEK, J., BIALASOVÁ, K. and GUHLOVÁ, P. Properties of (Ti,Nb)Al-(Ti,Nb)5Si eutectic composite. Compos. Struct. 2010. vol. 92, pp. 1440-1448. DOI: 10.1016/j.compstruct.2009.11.010.

[5] XIANG, L., WANG, F., ZHU, J. and WANG, X. Mechanical properties and microstructure of $\mathrm{Al}_{2} \mathrm{O}_{3} / \mathrm{TiAl}$ in situ composites doped with $\mathrm{Cr}_{2} \mathrm{O}_{3}$. Mater. Sci. Eng. A. 2011. vol. 528, pp. 3337-3341. DOI: 10.1016/j.msea.2011.01.006.

[6] NIU, H.Z., XIAO, S.L., KONG, F.T., ZHANG, C.J. and CHEN, Y.Y. Microstructure characterization and mechanical properties of $\mathrm{TiB}_{2} / \mathrm{TiAl}$ in situ composite by induction skull melting process. Mater. Sci. Eng. A. 2012. vol. 532, pp. 522-527. DOI: 10.1016/j.msea.2011.11.017.

[7] CHEN, R., FANG, H., CHEN, X., SU, Y., DING, H., GUO, J. and FU, H. Formation of TiC/Ti ${ }_{2} A I C$ and $\alpha_{2}+\gamma$ in insitu TiAl composites with different solidification paths. Intermetallics. 2017. vol. 81, pp. 9-15.

DOI: 10.1016/j.intermet.2017.02.025. 
[8] LIU, Y., HU, R., YANG, J. and LI, J. Tensile properties and fracture behavior of in-situ synthesized $\mathrm{Ti}_{2} \mathrm{AIN} / \mathrm{Ti} 48 \mathrm{Al} 2 \mathrm{Cr} 2 \mathrm{Nb}$ composites at room and elevated temperatures. Mater. Sci. Eng. A. 2017. vol. 679, pp. 7-13. DOI: 10.1016/j.msea.2016.09.105.

[9] WITUSIEWICZ, V.T., HALLSTEDT, B., BONDAR, A.A., HECHT, U., SLEPTSOV, S.V. and VELIKANOVA, T.Y. Thermodynamic description of the Al-C-Ti system. J. Alloys Compd. 2015. vol. 623, pp. 480-496.

[10] BARSOUM, M.W., ALI, M. and EL-RAGHY, T. Processing and characterization of $\mathrm{Ti}_{2} \mathrm{AIC}_{\mathrm{C}} \mathrm{Ti}_{2} \mathrm{AIN}$, and

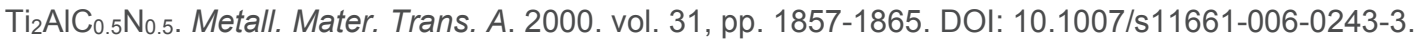

[11] SCABAROZI, T., GANGULY, A., HETTINGER, J.D., LOFLAND, S.E., AMINI, S., FINKEL, P., EL-RAGHY, T. and BARSOUM, M.W. Electronic and thermal properties of Ti $i_{3} \mathrm{Al}\left(\mathrm{C}_{0.5}, \mathrm{~N}_{0.5}\right)_{2}, \mathrm{Ti}_{2} \mathrm{Al}\left(\mathrm{C}_{0.5}, \mathrm{~N}_{0.5}\right)$ and Ti 2 AIN. J. Appl. Phys. 2008. vol. 104, pp. 1-7. DOI: 10.1063/1.2979326.

[12] KLIMOVÁ, A. and LAPIN, J. Effects of $C$ and $N$ additions on primary MAX phase particles in intermetallic Ti-Al$\mathrm{Nb}$-Mo matrix in-situ composites prepared by vacuum induction melting. Kov. Mater. 2019. vol. 57, pp. 151-157.

[13] ČEGAN, T. and SZURMAN, I. Thermal stability and precipitation strengthening of fully lamellar Ti-45AI-5Nb-0.2B0.75C alloy. Kovove Mater. 2017. vol. 55, pp. 421-430. DOI: 10.4149/km_2017_6_421.

[14] KAMYSHNYKOVA, K. and LAPIN, J. Grain refinement of cast peritectic TiAl-based alloy by solid-state phase transformations. Kovove Mater. 2018, vol. 56, pp. 277-287. DOI: 10.4149/km_2018_5_277.

[15] WANG, L., OEHRING, M., LORENZ, U., STARK, A. and PYCZAK, F. New insights into perovskite-Tii AIC precipitate splitting in a Ti-45Al-5Nb-0.75C alloy by transmission electron microscopy. Intermetallics. 2018. vol. 100, pp. 70-76. DOI: 10.1016/j.intermet.2018.06.006.

[16] GABRISCH, H., STARK, A., SCHIMANSKY, F.P., WANG, L., SCHELL, N., LORENZ, U. and PYCZAK, F. Investigation of carbides in Ti-45Al-5Nb-xC alloys $(0 \leq x \leq 1)$ by transmission electron microscopy and high energy-XRD. Intermetallics. 2013. vol. 33, pp. 44-53. DOI: 10.1016/j.intermet.2012.09.023.

[17] YANG, C., WANG, F., Al, T. and ZHU, J. Microstructure and mechanical properties of in situ TiAl/Ti $2 \mathrm{AIC}$ composites prepared by reactive hot pressing. Ceram. Int. 2014. vol. 40, pp. 8165-8171. DOI:10.1016/j.ceramint.2014.01.012.

[18] YANG, F., KONG, F.T., CHEN, Y.Y. and XIAO, S.L. Effect of spark plasma sintering temperature on the microstructure and mechanical properties of a Ti 2 AIC/TiAl composite. J. Alloys Compd. 2010, vol. 496, pp. 462466. DOI: 10.1016/j.jallcom.2010.02.077.

[19] YEH, C.L. and CHEN, J.H. Combustion synthesis of $\left(\mathrm{Ti}_{1-\mathrm{x}} \mathrm{Nb}_{\mathrm{x}}\right)_{2} \mathrm{AIC}$ solid solutions from elemental and $\mathrm{Nb}_{2} \mathrm{O}_{5} / \mathrm{Al}_{4} \mathrm{C}_{3}$-containing powder compacts. Ceram. Int. 2011, vol. 37, pp. 3089-3094. DOI: 10.1016/j.ceramint.2011.05.045.

[20] FANG, H., CHEN, R., CHEN, X., YANG, Y., SU, Y., DING, H. and GUO, J. Effect of Ta element on microstructure formation and mechanical properties of high-Nb TiAl alloys. Intermetallics. 2019, vol. 104, pp. 43-51. DOI: 10.1016/j.intermet.2018.10.017.

[21] FANG, H., CHEN, R., YANG, Y., SU, Y., DING, H., GUO, J. and FU, H. Role of graphite on microstructural evolution and mechanical properties of ternary TiAl alloy prepared by arc melting method. Mater. Des. 2018. vol. 156, pp. 300-310. DOI: 10.1016/j.matdes.2018.06.048.

[22] ŠTAMBORSKÁ, M. and LAPIN, J. Effect of anisotropic microstructure on high-temperature compression deformation of CoCrFeNi based complex concentrated alloy. Kovove Mater. 2017. vol. 55, pp. 369-378.

[23] SKLENIČKA, V., KUCHAROVÁ, K., KRÁL, P., KVAPILOVÁ, M. and DVORÁK, J. Applicability of empirical formulas and fractography for assessment of creep life and creep fracture modes of tempered martensitic $9 \% \mathrm{Cr}$ steel. Kovove Mater. 2017. vol. 55, pp. 69-80. DOI: 10.4149/km_2017_2_69.

[24] HARDING, R.A. Recent developments in the induction skull melting and investment casting of titanium aluminides. Kovove Mater. 2004. vol. 42, pp. 225-241.

[25] SIMPKINS, R.J., ROURKE, M.P., BIELER, T.R. and MCQUAY, P.A. The effects of HIP pore closure and age hardening on primary creep and tensile property variations in a TiAI XD TM alloy with $0.1 \mathrm{wt} \%$ carbon. Mater. Sci. Eng. A. 2007. vol. 463, pp. 208-215. DOI: 10.1016/j.msea.2006.09.114. 